\title{
Gaining an insight into the importance of
} each inhalation manoeuvre parameter using altered patients' inhalation profiles

\author{
Mohamad Abadelah $^{\mathrm{a}, \mathrm{b}}$, Gaballa Abdallac $^{\mathrm{c}}$ Henry Chrystyn ${ }^{\mathrm{d}}$, Hassan Larhrib $^{\mathrm{a}}{ }^{*}$ \\ aDepartment of Pharmacy and Pharmaceutical Sciences, University of Huddersfield, Huddersfield HD1 \\ 3DH, United Kingdom

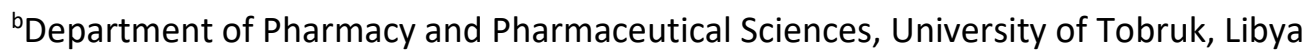 \\ 'Department of Engineering and Technology, University of Huddersfield, Huddersfield, HD1 3DH, UK. \\ IInhalation Consultancy Ltd, Yeadon, Leeds, LS19 7SP, United Kingdom \\ *Corresponding author at Department of Pharmacy and Pharmaceutical Sciences, University of
} Huddersfield, Queensgate, Huddersfield HD1 3DH, United Kingdom.

Tel: +44 1484 473051: fax: +44 1484472182.

Email addresses:

Hassan Larhrib e.Larhrib@hud.ac.uk ,Mohamad Abadelah, Mohamad.abadelah@yahoo.com , Henry Chrystyn, h.chrystyn@gmail.com, Gaballa Abdalla,_Aloklijaballh@yahoo.com

Target journal = Journal of drug delivery science and Technology (JDDST)

Number of Figures: 4

Number of tables: 5

Word count: 5128

Abbreviations: IP, inhalation profile, $\mathrm{ACl}$, Andersen Cascade Impactor; DPIs, dry powder inhalers; FPD, fine particle dose; FPF, fine particle fraction; HPLC, high performance liquid chromatography; PIF, Peak inhalation flow; IT, inhalation time; Vin, inhaled volume; LOD, limit of detection; LOQ, limit of quantification; MMAD, mass median aerodynamic diameter; PIL, patient information leaflets; RA, residual amount; DD, delivered dose; TRD, total recovered dose 


\section{ABSTRACT}

33 The aerodynamic particle size distribution (APSD) and dose emission characteristics of

34 indacaterol Breezhaler have been measured using ex-vivo methodology and altering original

35 COPD inhalation manoeuvre profiles to investigate the influence of inspiratory parameters

36 namely, the peak inhalation flow (PIF), inhalation acceleration rate (ACIM) and inhaled volume

37 (Vin) by keeping two parameters fixed and varying the other one.

38 All inhalation parameters had an impact on the dose emission, dose emptying from the 39 capsule/device in the order of PIF>Vin>ACIM. ACIM and Vin have almost an equal effect on the 40 delivered dose (DD) and the fine particle dose (FPD) but the impact of the PIF was the most

41 pronounced. PIF also had the greatest impact on the mass median aerodynamic diameter

42 (MMAD). Producing an optimal inhalation manoeuvre combining the highest PIF, ACIM and Vin

43 in one single inhalation would improve both the quantity and the quality of the aerosol. Making

44 two separate inhalation from each prepared dose would also be useful. This ex-vivo methodology

45 replaying altered COPD profiles with the breath simulator allows an insight on the importance of 46 each inhalation manoeuvre parameter which would have not been possible using conventional 47 in-vitro Pharmacopoeial methodology.

\section{Keywords:}

49 Andersen cascade impactor ( $\mathrm{ACl}$ ), Peak inhalation flow (PIF), Inhalation volume (Vin),

50 Acceleration rate (ACIM), Breath simulator (BRS) and Onbrez Breezhaler ${ }^{\circledR}$ 


\section{1. Introduction}

52 The drug delivery to the local site of action in the lungs and reducing the systemic side effect is

53 paramount in the treatment and management of respiratory disorders such as asthma and

$54 \operatorname{COPD}[1,2]$. Thus, the pulmonary route is the important route of drug administration in the

55 treatment of respiratory diseases. In order to deliver the medication via the inhalation route,

56 different inhaler devices are available nebulisers, pressurised metered dose inhalers (pMDIs) and

57 dry powder inhalers (DPIs). The latter is becoming the most widely used device. The dose emitted

58 from a DPI operates upon the inhalation manoeuvre generated by the patient, which means no

59 co-ordination is required between dose actuation and the inhalation manoeuvre, as the case with

60 most pMDIs [1,3].

61 The amount and the quality of the dose emitted from a DPI is dependent on its formulation. The

62 performance of a DPI formulation depends on detachment of drug particles from the carrier

63 surface and deaggregation of drug agglomerates during aerosolization, any factor that affects the

64 drug-carrier interaction may also affect drug delivery and deposition. Several parameters have

65 been identified including carrier size and size distribution, shape and surface roughness. The

66 latter has been identified to be closely related to surface energy and the adhesion force between

67 drug and carrier[4].The design and resistance of the device and inhalation profiles (IPs)

68 characteristics of the inhalation manoeuvre made by a patient are equally important in enhancing

69 aerosol performance from DPIs [5-7].

70 The patient's IP is characterised by three factors namely the peak inhalation flow (PIF), the

71 inhaled volume (Vin) and initial acceleration at the start of the inhalation manoeuvre

72 (ACIM) $[8,9]$.There is a large inter-individual variability of IPs made by patients with asthma and 
73 chronic obstructive pulmonary disease (COPD) when they inhale through DPIs [10,11] and

74 therefore prescribing the right inhaler to the right patient together with training them how to 75 use the device are crucial $[7,12,13]$.

76 Dose de-aggregation and the clinical efficacy of DPIs is governed by the characteristics of the IP 77 generated by the patient $[3,14]$. In-vitro assessment of DPIs using compendial methodologies 78 (USP, 2014) to probe the total emitted dose (TED) and aerodynamic particle size distribution 79 (APSD) of the inhaled products are quality control tests that are not reflective of real life patient use $[8,15]$. Nevertheless, since the systemic drug delivery is a function of the total emitted dose 81 (TED), which acts as an indicator of systemic safety, while lung deposition is a function of the fine 82 particle dose (FPD), a marker of dose efficacy $[16,17]$ then these in-vitro methodologies do 83 provide some useful insights related to patient use. To compliment this, the European Medicines 84 Agency (EMA) have recommended that these should be measured using a range of inhalation 85 PIFs achieved by the patients (EMA, 2006). However, these methods use a vacuum pump to 86 generate an inhalation profile which is not achievable by a human $[8,9,15]$.

87 We have adapted the compendial in-vitro methodologies, based on using the Andersen Cascade Impactor $(\mathrm{ACl})$, by using the inhalation profiles of patients instead of the traditional vacuum 89 pump [9]. Using this ex-vivo methodology, inhalation manoeuvre parameters such as PIF, Vin and ACIM have been shown to affect the dose delivery from DPIs[9,15]. During routine real life use 91 the contribution of each of the inhalation parameters on dose emission from a DPI is not known. 92 Our previous study in-vitro using Dose unit sampling apparatus (DUSA) and Andersen Cascade 93 impactor $(\mathrm{ACl})[18]$ allowed us to investigate the effects of the PIFs and Vins separately by fixing 
aerodynamic characteristics of inhaled aerosol. Our study in-vitro showed that inhaled volume becomes more important in improving dose emission and drug deposition, especially at low PIF. Due to the square wave inhalation profile of this in-vitro method dictated by the vacuum pump, the PIF is reached instantly upon actuation of the dose contrary to the gradual increase in ACIM for a bell-shaped inhalation profile of a patient making correlations difficult and the results from the in-vitro study are overestimated in comparison of what is happening in-vivo .Using our exvivo method a patient profile can be altered by varying one inhalation manoeuvre parameter at a time whilst fixing the two other parameters to help understand the impact of each inhalation parameter and its contribution to overall drug emission and drug deposition. Therefore, this study focuses on the use of COPD patients' altered IPs to investigate the effect of each inspiratory parameter (PIF, Vin and ACIM) on the overall dose emission and APSD of indacaterol from an

Onbrez Breezhaler ${ }^{\circledR}$.

\section{Materials and methods}

\subsection{Inhaler device}

109 Onbrez Breezhaler ${ }^{\circledR}$ (Novartis Pharmaceuticals Ltd, CH) used in the study. Each capsule contains 110 indacaterol maleate equivalent to $150 \mu \mathrm{g}$ of indacaterol.

\section{$111 \quad$ 2.2. Altered inhalation profiles}

112 The IPs of 37 patients with different COPD severity aged 55-79 with a mean age of 66, when they 113 inhaled through a Breezhaler ${ }^{\circledR}$ loaded with an empty capsule were measured using an inhalation 114 profile recorder [11] . The Breezhaler ${ }^{\circledR}$ is a low resistance device with an intrinsic resistance of $0.0177(\mathrm{kPa})^{0.5}\left(\mathrm{~min} \mathrm{~L}^{-1}\right)[19]$. The patients were given the patient information leaflet (PIL) to read and trained to inhale as fast as they can from the start of the inhalation manoeuvre and continue 
117 for as long as possible. The inspiratory parameters (e.g., PIF, ACIM and Vin) were obtained from 118 each profile [10]

119 The IPs with a PIF of low (40 L/min) medium (65 L/min) and high ( $85 \mathrm{~L} / \mathrm{min})$ flows were chosen.

120 The ACIM and Vin of these profiles were altered to obtain Vin values of 1,2 and $3 \mathrm{~L}$ and $\mathrm{ACIM}$

121 values of 2,4 and $8 \mathrm{~L} / \mathrm{s}^{2}$, the total number of altered IPs in the present study were 27 IPs. The

122 inhalation volume was altered by increasing or decreasing the inhalation time (Ti) after the PIF

123 of the profile. The ACIM was altered by increasing or decreasing the time to PIF.

12427 profiles were used (9 profiles varying the PIF from low (40 L/min) to medium (65 L/min) to 125 high flow rate $(85 \mathrm{~L} / \mathrm{min})$ but fixing the ACIM and Vin, 9 profiles varying the ACIM from 2 to 4 to $1268 \mathrm{~L} / \mathrm{s}^{2}$ but with fixed PIF and Vin and finally 9 profiles with varying the Vin from low (1L) to 127 medium (2 L) to high (3 L) but with fixed PIF and ACIM).

\subsection{Experimental set-up}

(a) Aerodynamic particle size distribution (APSD)

Figure 1 , previously described by $[8,9]$ provides a schematic design of the method used to identify the APSD. The Andersen Cascade Impactor ( $\mathrm{ACl}$; Copley Scientific Ltd, UK) was set up at either 60 or $90 \mathrm{~L} / \mathrm{min}$ using the appropriate stages and pre-separator with the required flow rate drawn through the $\mathrm{ACl}$ using a dry powder flow controller (TPK2100; Copley Scientific Ltd, UK) and vacuum pump (HCP5; Copley Scientific Ltd, UK). A mixing inlet was placed between the adult version of the Alberta's Idealised Throat (AIT; Copley Scientific Ltd, UK) and the pre-separator of the $\mathrm{ACl}$. Supplementary air from a compressed air source was introduced into the $\mathrm{ACl}$, through the side arm of the mixing inlet, at the same flow rate that was drawn through the $\mathrm{ACl}$, so that the airflow at the mouthpiece of the AIT was zero $(0 \mathrm{~L} / \mathrm{min})$. During the set-up a flow meter was 
139 attached to the AIT to ensure zero flow at the mouthpiece when adjusting the supplementary

140 flow to equal the air drawn through the ACl. A breath simulator (BRS 3000, Copley Scientific

141 Ltd), was programmed with the inhalation flow against time data of each IP. It was positioned

142 between the supplementary air and the mixing inlet. When the programmed IP was drawn from

143 the supplementary air, the IP was replayed through the DPI in situ at the mouthpiece of the AIT

144 because of the constant flow drawn through the $\mathrm{ACl}$ via the dry powder controller unit. Thus, the

145 IPs facilitated dose de-aggregation and emission of indacaterol from the capsule loaded in the

$146 \mathrm{Breezhaler}^{\circledR}$, into the $\mathrm{ACl}$. For each determination, three separate capsules were aerosolised into

147 the $\mathrm{ACl}$ by replaying the IP for each capsule and three separate dose emission determinations

148 were made $(n=3)$ for each IP.

149 (b) Delivered dose and residual amounts

150 The delivered dose (DD) was determined using a dose unit sampling unit (DUSA; Copley Scientific

151 Ltd, UK). The method is similar to that of the pharmacopoeias (USP, 2014) except that the vacuum

152 pump was replaced by inhalation profiles drawn through the DUSA using the breath simulator

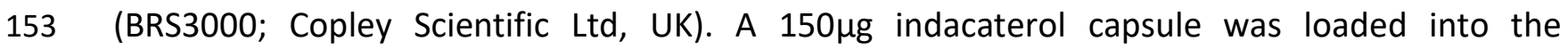

154 Breezhaler $^{\circledR}$, according to the instructions for use, and the inhaler was inserted into the

155 mouthpiece of the DUSA. An inhalation profile was then replayed, and the emitted dose was

156 captured in the DUSA. Each determination was carried out three times for each IP. The delivered

157 dose (DD) was determined after recovering the dose emitted into the DUSA and the residual

158 amount from that left in the capsule and device 
160

161 The amount of indacaterol deposited on each stage of the $\mathrm{ACl}$ and the final filter, the pre-

162 separator, AIT, and the mixing inlet were recovered by appropriate rinsing followed by 163 measurement using a validated HPLC method.

164 The HPLC system used for samples quantification was Prominence liquid chromatography LC-20

165 AT (Shimadzu, UK). The specifications of the system component are as follow

\subsection{HPLC assay}

- Pump: LC-20AT prominence pump. Oven: column oven (CT0-10AS VP)

- Autosampler: Prominence Auto Sampler (SIL-20A HT) fitted with a $200 \mu \mathrm{L}$ loop (Shimadzu Ltd, UK)

- Degasser: Prominence degasser (DGU-20A5) (Shimadzu Ltd, UK)

- Detector: SPD-20A prominence UV-vis detector (Shimadzu Ltd, UK)

The HPLC method used was validated using Dexamethasone as an internal standard. The limit of quantification and limit of detection for indacaterol were 0.17 and $0.07 \mu \mathrm{g} / \mathrm{mL}$ respectively. A summary of the HPLC method is shown in Table $1[8,20]$

\subsection{Data Analysis}

The Copley Inhaler Testing Data Analysis Software (CITDAS version 2.0, Copley Scientific Ltd, UK) was used to calculate the aerodynamic dose emission parameters.

The total emitted dose (TED) was obtained from the cumulative amounts of indacaterol deposited in the Alberta's throat (IAT), the pre-separator, mixing inlet and all the stages of the $\mathrm{ACl}$. The FPD was the mass associated with particles $<5 \mu \mathrm{m}$ and the extra fine particle dose (EFPD) was the mass of powder associated with particles $<2 \mu \mathrm{m}$ [21]. The fine particle dose was 
expressed as a \% of the label claim and the fine particle fraction (FPF) was the FPD divided by the TED. The MMAD was the size corresponding to the 50th percentile of the cumulative massweighed distribution of the amount deposited in the $\mathrm{ACl}$. The geometric standard deviation

184 (GSD) indicates the variability in the aerosol particle size. The GSD is representing the dispersion of the inhaled particles whereas particles with $\leq 1.2$ are monodisperse and particles with GSD of $\geq 1.2$ are polydisperse. Large particle mass (LPM) was calculated as mass of the particles $>5 \mu \mathrm{m}$ 187 deposited in the upper part of the $\mathrm{ACl}$.

The delivered dose (DD) was the total amount deposited in the DUSA, the residual amount (RA) was the amount left in the device and capsule after drawn a inhalation profile and the total 190 recovered dose (TRD) was the sum of DD and RA. SPSS version 16.0 software (SPSS Inc., Chicago, USA) was used for the statistical analysis. A two192 way analysis of variance (ANOVA) was used to determine any significant differences between the 193 DD, FPD, \%FPF, MMAD between different inhalation profiles.

\section{3. Results}

195 To study the effect of the PIF, we maintained the ACIM and Vin fixed. To study the impact of the 196 ACIM, we maintained the PIF and Vin fixed and finally to investigate the impact of the Vin, we 197 maintained the PIF and ACIM fixed and the results are summarised in Tables (2, 3 and 4). Dose 198 delivery uniformity and dose emission from an Onbrez Breezhaler ${ }^{\circledR}$ was also conducted using 199 DUSA for the same profiles (Table 5). At any fixed ACIM and Vin, increasing the PIF from 40 to 85 $200 \mathrm{~L} / \mathrm{min}$ resulted in a significant increase $(p<0.05)$ in the DD, FPD, EFPD and a significant reduction $201(p<0.05)$ in the RA and MMAD. The effect of the PIF on the aerodynamic characteristics of the 
emitted dose was even more pronounced when the PIF was combined with the highest ACIM (8 $\mathrm{L} / \mathrm{s}^{2}$ ) and the highest Vin (3 L) Tables (2, 3 and 4).

At any fixed PIF and Vin, the FPD and DD increased significantly $(p<0.05)$ with increasing the ACIM (Figure 2, Table 5). RA showed also some marginal decrease but still significant $(p<0.05)$ (Table 5). Whereas, the MMAD was not affected by the ACIM (Figure 3). At any fixed PIF and ACIM, the DD (Table 5), and FPD (Figure2) increased significantly with increasing the Vin, whereas, RA (Table 5) showed a significant decrease $(p<0.05)$ but MMAD (Figure 3 ) was not affected with the Vin. Most changes in the aerodynamic dose emission characteristics of indacaterol were observed by combining all optimal inhalation manoeuvre parameters (highest

211 PIF, highest ACIM and highest Vin) (Tables 2,3 and 4). About 50\% of the indacaterol $150 \mu \mathrm{g}$

212 nominal dose was deposited in the impactor as large particle mass (LPM) (Tables 2,3 and 4)

213 irrespective of the PIF, ACIM and Vin. GSD values are $>1.2$ and showed no significant variation 214 with the PIF, ACIM and Vin (Tables, 2,3 and 4). Dose delivery study with the DUSA corroborated 215 with the impactor study with regards to the DD and RA (Table 5).

\section{Discussion}

217 Onbrez Breezhaler ${ }^{\circledR}$ dose emission and aerodynamic characteristics were studied previously 218 [18,22-24]. This device was chosen because patients were able to generate a wide range of PIFs, 219 Vins and ACIMs. Previous In-vivo studies showed that not all the patients were able to generate $2204 \mathrm{kPa}$ pressure drop across the inhaler with $4 \mathrm{~L}$ inhalation volume as recommended by the 221 pharmacopoeia to assess the in-vitro dose emission from DPIs [10,11]. Patients using Breezhaler ${ }^{\circledR}$ 222 were able to inhale with least inspiratory effort and generate a high PIF when compared to Elipta ${ }^{\circledR}$ 
223 and Handihaler ${ }^{\circledR}[22,24,25]$. Breezhaler ${ }^{\circledR}$ requires a minimum PIF of $30 \mathrm{~L} / \mathrm{min}$ and optimal PIF of

$22460 \mathrm{~L} / \mathrm{min}$ when compared to Genuair ${ }^{\circledR}$ which requires an optimal flow $>45 \mathrm{~L} / \mathrm{min}$ [26]

225 Using patient IPs, the major influence on dose emission and its characteristics was found to be 226 the PIF. This flow dependent dose emission of indacaterol from the Breezhaler ${ }^{\circledR}$ is consistent with 227 that reported by others [22,23]. Also, the results are consistent with the dose emission 228 characteristics of glycopyrronium from the Breezhaler ${ }^{\circledR}[24]$. The largest difference was found to 229 be between 40 and $65 \mathrm{~L} / \mathrm{min}$ suggesting that $65 \mathrm{~L} / \mathrm{min}$ could be regarded as the cut-off inhalation 230 flow. This is faster than that previously reported [27]. Using inhalation profiles amongst the 37 231 COPD patients we studied 9 inhaled profiles $<65 \mathrm{~L} / \mathrm{min}$. Previous studies have shown that out of 23226 patients only one patient achieving a PIF of $<52$ L/min [22], while Colthorpe et al., (2013) 233 reported that only 2 patients achieving a PIF $<65$ L/min[24]. In our previous inhalation profiles 234 performance study, patients inhaling through Breezhaler ${ }^{\circledR}$ were able to generate an average Vin 235 and $\mathrm{ACIM}$ of $2.1 \mathrm{~L}$ and $4.2 \mathrm{~L} / \mathrm{s}^{2}[8]$.

236 The ex-vivo methodology was used to identify the impact of each of the inhalation manoeuvre 237 parameter (PIF, Vin and ACIM) on the aerodynamic and dose emission characteristics of 238 indacaterol $150 \mu \mathrm{g}$ capsules from a Breezhaler ${ }^{\circledR}$. It has been reported that these parameters play 239 an important role in both dose emission and drug deposition into the lungs $[8,9,15]$ but it's very 240 difficult to differentiate which one of these parameters has the most dominant effect. The 241 information provided in the patient information leaflets (PIL) when inhaling through DPIs is 242 vague, such as inhale as 'inhale forcefully'. The meaning of this phrase is clear to the aerosol 243 formulation scientists (i.e., to achieve an optimal PIF, ACIM and Vin) but not for all patients. This 244 will result in the misuse of the inhaler device by the patient, resulting in the patient getting a sub- 
245 optimal dose. Knowing which parameter of the inhalation manoeuvre is the most important will

246 ease patient's training and education by the inhalation health care practitioners to help the

247 patient manage their own disease. Unfortunately, no data is available in the literature regarding

248 the influence of each inhalation parameter. Compendial methods use a vacuum pump that

249 provides an unachievable fast acceleration and square wave inhalation profile that is not possible

250 for any human to replicate. Also, recommendations to use an inhalation flow corresponding to a

251 pressure drop of $4 \mathrm{kPa}$ and an inhaled volume of $4 \mathrm{~L}$ is only achieved by very small numbers of

252 patients $[10,11]$.The compendial methodologies provide dose emission data that uses optimal

253 inhalations and so can only be regarded as quality control data and not reflective of patient use.

254 Most commercially available DPIs are a breath actuated devices, and the dose emission from the

255 inhaler relies on the above mentioned inspiratory parameters to generate particles within the

256 respirable range $(\leq 5 \mu \mathrm{m})$ with the greatest tendency for lung deposition $[28,29]$. The intrinsic

257 device resistance is an important factor that determines the extent of the patient's ability to

258 generate the required pressure drop inside the device for effective dose de-aggregation and

259 dispersion $[30,31]$. Indacaterol Breezhaler ${ }^{\circledR}$ belongs to low resistance devices category with a PIF

260 of $100 \mathrm{~L} / \mathrm{min}$ and above to generate $4 \mathrm{kPa}$ pressure drop [22]. To attain a pressure, drop of $4 \mathrm{kPa}$

261 in the Breezhaler ${ }^{\circledR}$ requires an inhalation flow of $107 \mathrm{~L} / \mathrm{min}$. This is above the recommended flow

262 to use cascade impactors, so it is useful to study dose emissions using inhalation profiles.

263 However, using the $\mathrm{ACl}$ and the Next Generation Impactor (NGI) using flows below 90 and 100

$264 \mathrm{~L} / \mathrm{min}$, respectively, is not recommended. Nevertheless although dose emission from the Onbrez

265 Breezhaler ${ }^{\circledR}$ is dependent on the inhalation flow rate $[18,22,23]$ knowledge of the dose emission

266 above these maximum flow is not important because dose de-aggregation and empty of the dose 
267 from the capsule and device should approach the nominal dose and, therefore, not clinically 268 significant. However, if a patient uses the Breezhaler ${ }^{\circledR}$ with an inhalation flow above $100 \mathrm{~L} / \mathrm{min}$ 269 oropharyngeal deposition will start to increase $[7,32]$

270 The dose emission study from various profiles was carried out using the DUSA (Table 5). To study

271 the impact of the PIF on the indacaterol dose emission, we fixed the values of both the Vin and

272 ACIM. DD increased significantly $(p<0.05)$ with the PIF at any fixed Vin and ACIM suggesting dose

273 emission flow rate dependency of the Onbrez Breezhaler ${ }^{\circledR}$ (Figure 4). The increase in the dose

274 emission was associated with a significant increase $(p<0.05)$ in the FPD (Figure 2$)$, extra fine

275 particle dose (EFPD) (Tables 2,3 and 4) and a reduction in the MMAD (Figure 3). For examples, at

276 the weakest $\operatorname{Vin}(1 \mathrm{~L})$ and $\operatorname{ACIM}\left(2 \mathrm{~L} / \mathrm{s}^{2}\right)$, DD increased from 116,80 (1.25) $\mu \mathrm{g}$ at $40 \mathrm{~L} / \mathrm{min}$ to 125.41

277 (0.73) at $85 \mathrm{~L} / \mathrm{min}$ (Table 5) and the corresponding FPD increased from 29.4 (0.7) $\mu \mathrm{g}$ to 34.7 (0.7)

$278 \mu \mathrm{g}$ (Figure 2), whereas the EFPD increased significantly $(p<0.05)$ from $19.7(1.1) \mu g$ to $25.2(0.3)$

$279 \mu \mathrm{g}$. The fine particles dose obtained for indacaterol was in line with clinical study conducted on 280 glycopyrronium bromide using the same inhaler device Breezhaler ${ }^{\circledR}$. FPF of approximately $36 \%$ 281 of the total emitted dose was generated in both studies suggesting the reliability of Breezhaler ${ }^{\circledR}$ 282 in delivering the same FPD irrespective of the drug used [33].

283 The residual amount (RA) left in the capsule and device also showed a substantial decrease with 284 increasing the PIF from $40 \mathrm{~L} / \mathrm{min}$ to $85 \mathrm{~L} / \mathrm{min}$ at a fixed ACIM and Vin (Figure 4). In the DUSA study 285 for example at the above mentioned weakest Vin (1 L) and ACIM (2 L/s $\left.{ }^{2}\right)$, the RA decreased from $28633.51(1.00) \mu \mathrm{g}$ at $40 \mathrm{~L} / \mathrm{min}$ to $22.76(0.54) \mu \mathrm{g}$ at $85 \mathrm{~L} / \mathrm{min}$ (Table 5). The impact of the PIF on 287 indacaterol dose emission, dispersion shown from the increase in the EFPD $\leq 2 \mu \mathrm{m}$, increasing 288 the amount of respirable particles reaching the distal stages of the impactor (FPD) and 
contributing to dose emptying is obvious. But the impact of the PIF on reducing the large particle mass (LPM) is not substantial as approximately $50 \%$ of the nominal dose was deposited and lost in the upper part of the impactor as LPM irrespective of the flow rate used.

The effect of the PIF on dose emission characteristics and dose retention is further enhanced by increasing the inhaled volume (Vin) and the acceleration of inhalation at the start of the inhalation manoeuvre (ACIM). For example, DD increased from 116.80 (1.25) $\mu \mathrm{g}$ at PIF (40L/min), $\operatorname{ACIM}\left(2 \mathrm{~L} / \mathrm{s}^{2}\right)$, Vin (1 L) (Table 5) to 134.83 (1.58) $\mu \mathrm{g}$ at PIF (85L/min), ACIM (8 L/s²), Vin (3 L) (Table 5). Similarly, the FPD increased from 29.4 (0.7) $\mu \mathrm{g}$ to 49.8 (1.0) $\mu \mathrm{g}$ (Figure 2), EFPD increased by two fold from $19.7(1.1) \mu \mathrm{g}$ to $39.16(0.2) \mu \mathrm{g}$, MMAD was reduced from $3.4(0.1)$ to $2.6(0.0) \mu \mathrm{m}$ (Figure 3) and dose retention in device and capsule was reduced by $50 \%$ from 33.51 (1.00) $\mu \mathrm{g}$ to 14.58 (2.44) $\mu \mathrm{g}$ (Table 5). Thus, by combining all optimal inhalation parameters, i.e., highest PIF, highest ACIM and the highest Vin in one single inhalation, the quantity and the quality of the inhaled indacaterol is improved to maximise drug delivery to the lungs, whilst providing more particles in the extrafine range $(\leq 2 \mu \mathrm{m})$ with high tendency for peripheral deposition.

The effect of ACIM could not be investigated using traditional pharmacopoeial methods, due to the square wave generated by the vacuum pump resulting in a rapid acceleration through the DPI, beyond what typical patient can generate during routine use [10]. However, this was made possible with the breath simulator. The impact of the ACIM alone was also investigated by fixing the PIF and the Vin. DD increased significantly $(p<0.05)$ with the ACIM at any fixed PIF and Vin (Table 5). The increase in the dose emission was accompanied with a significant $(p<0.05)$ increase in the FPD (Figure 2), effective extra fine dose (EFPD) showed a marginal increase, almost no significant effect on the MMAD (Figure 3). The impact of the PIF on the DD, FPD, EFPD and 
311 MMAD was more significant $(p<0.05)$ than the ACIM. Since the acceleration rate is involved at

312 the start of the inhalation manoeuvre and from these results it seems that the ACIM has more 313 effect on dose emission and detachment of the indacaterol from the surface of the carrier to 314 maximise the amount of aerosol exiting the device increasing DD (Figure 4) and FPD (Figure 2), 315 but the effect of ACIM on drug dispersion is limited as shown by EFPD (Tables 2,3 and4) and 316 MMAD (Figure 3) results which were marginally affected by the ACIM. For examples, at the 317 weakest PIF (40 L/min) and Vin (1 L), DD increased from $116.80(1.25) \mu \mathrm{g}$ at $2 \mathrm{~L} / \mathrm{s}^{2}$ to 121.31 $318(0.16) \mu \mathrm{g}$ at $8 \mathrm{~L} / \mathrm{s}^{2}$ (Table 5) and FPD increased from $29.4(0.7) \mu \mathrm{g}$ to 34.7 (0.7) $\mu \mathrm{g}$ (Figure 2), 319 whereas the EFPD increased from 19.7 (1.1) $\mu \mathrm{g}$ to 25.2 (0.3) $\mu \mathrm{g}$ (Tables 2). The residual amount 320 (RA) left in the capsule and device showed a slight decrease with increasing the ACIM from $2 \mathrm{~L} / \mathrm{s}^{2}$ 321 to $8 \mathrm{~L} / \mathrm{s}^{2}$ (Figure 4). MMAD showed almost no significant variation with the ACIM (Figure 3).

322 This detailed study on the effect of the initial acceleration of the inhalation manoeuvre (ACIM) 323 showed its importance in dose emission of the inhaled indacaterol which is in accordance with 324 other authors $[9,14,15]$. Patients may achieve the same PIF and Vin but with different 325 accelerations. The one inhaling fast through Onbrez Breezhaler ${ }^{\circledR}$ can benefit more from the 326 inhaled dose.

327 Effect of the inhaled volume (Vin)

328 Inhalation volume (Vin) is another inhalation manoeuvre parameter to be considered when 329 evaluating the performance of DPIs. The Pharmacopoeial DPIs testing in-vitro suggested that a 330 Vin of $4 \mathrm{~L}$ should be drawn through the inhaler. However, most of the patients with asthma and 331 COPD were unable to achieve this value, and only a few patients were able to exceed $2 \mathrm{~L}$ 332 inhalation volume with a mean value $\geq 2 \mathrm{~L}[10,11,34]$. The inhaled volumes used to quantify the 
aerodynamic particle size distribution of inhaled indacaterol exceeds the internal volume of the $\mathrm{ACl}$ ( $1.155 \mathrm{~L}$ ) [35] to allow sufficient sampling time for the aerosol bolus transfer from the inhaler device to distal stages of the $\mathrm{ACl}[36,37]$.

The impact of the Vin at a fixed PIFs and ACIMs was investigated. For example, at the lowest PIF (40 L/min) and at any ACIM, increasing the Vin from $1 \mathrm{~L}$ to $3 \mathrm{~L}$ increased significantly $(p<0.05)$ the DD from $116.80(1.25) \mu \mathrm{g}$ to $123.98(0.44) \mu \mathrm{g}$ at ACIM of $2 \mathrm{~L} / \mathrm{s}^{2}$, from $117.96(2.08) \mu \mathrm{g}$ to $124.61(2.65) \mu \mathrm{g}$ at $\mathrm{ACIM}$ of $4 \mathrm{~L} / \mathrm{s}^{2}$ and from $121.31(0.16) \mu \mathrm{g}$ to $127.30(1.35) \mu \mathrm{g}$ at $8 \mathrm{~L} / \mathrm{s}^{2}$ (Table 5). It is interesting to note that the impact of the Vin on the DD is less pronounced at high ACIM (8L/s $\mathrm{s}^{2}$ and High PIF ( $85 \mathrm{~L} / \mathrm{min}$ )(Figure 4). For example, at the highest PIF ( $85 \mathrm{~L} / \mathrm{min}$ ) and the highest ACIM $8 \mathrm{~L} / \mathrm{s}^{2}$ (Table 5), the DD showed only slight but significant increase $(p<0.05)$ from 129.40 (1.68) $\mu \mathrm{g}$ to $134.83(1.58) \mu \mathrm{g}$ with increasing the Vin from $1 \mathrm{~L}$ to $3 \mathrm{~L}$ respectively. When the PIF and ACIM are low (e.g., PIF (40 L/min) and ACIM (2 L/s $)$ increasing the inhaled volume can be used to promote drug emission with a subsequent increase in the FPD (Figure 2). The importance of Vin was in agreement with previous studies carried out by Abadelah et al., (2017) Easyhaler ${ }^{\circledR}[38]$ Breezhaler $^{\circledR}[18]$. The impact of the Vin on the FPD is significant $(p<0.05)$ and this is obvious from Figure 2 . The increase in the Vin was associated with a significant $(p<$ 0.05) increase in the DD (Figure 4) and FPD (Figure 2) irrespective of the PIF and ACIM. This shows the importance of the Vin in promoting drug delivery to the lungs from capsule based DPIs such as Onbrez Breezhaler ${ }^{\circledR}$. The EFPD is marginally increased with the Vin, whereas MMAD (Figure 3) showed almost no change with the Vin suggesting that the Vin is involved more in mass transfer rather than aerosol dispersion to cause a further decrease in the MMAD as shown from the present results (Figure 3 ). The Vin has a significant effect $(p<0.05)$ on the RA left in the 
355 capsule and device as shown from DUSA study (Figure 4). For example, at the weakest PIF (40 $356 \mathrm{~L} / \mathrm{min})$ and $\operatorname{ACIM}\left(2 \mathrm{~L} / \mathrm{s}^{2}\right)$, the RA significantly reduced $(\mathrm{p}<0.05)$ from $33.51(1.00) \mu \mathrm{g}$ to 24.05 357 (1.01) $\mu \mathrm{g}$ with increasing the Vin from 1 to $3 \mathrm{~L}$ (Table 5) and on the other hand at the same PIF 358 (40 L/min) and Vin $1 \mathrm{~L}$, increasing the ACIM from $2 \mathrm{~L} / \mathrm{s}^{2}$ to $8 \mathrm{~L} / \mathrm{s}^{2}$ has promoted capsule and device emptying but significantly $(p<0.05)$ to a lesser extent when compared to the Vin (Table 5$)$. For example, at a fixed PIF (40 L/min) and $1 \mathrm{~L}$ Vin, increasing the ACIM from 2 to $8 \mathrm{~L} /{ }^{\mathrm{s}}$ has reduced the RA from $33.51(1.00) \mu g$ to 27.98 (2.77) $\mu \mathrm{g}$, this reduction in the RA was smaller compared to the Vin (Table 5). The most efficient inhalation manoeuvre parameter with regards to capsule and device emptying was PIF $>$ Vin $>A C I M$. The residual amount was reduced by $50 \%$ by combining all the inhalation manoeuvre parameters to their optimal values (i.e., increasing the PIF from 40 $\mathrm{L} / \mathrm{min}$ to $85 \mathrm{~L} / \mathrm{min}$; $\mathrm{ACIM}$ from $2 \mathrm{~L} / \mathrm{s}^{2}$ to $8 \mathrm{~L} / \mathrm{s}^{2}$; Vin from $1 \mathrm{~L}$ to $3 \mathrm{~L}$ ). It is interesting to note that complete emptying of the capsule and device is still a challenge irrespective of the inhalation manoeuvre. Thus, more work on the inhaler device is needed to improve dose emptying from capsule based devices such as Onbrez Breezhaler ${ }^{\circledR}$.

The $\beta$-receptors are abundant in the alveolar wall a region where no smooth muscle exists and

371 whose functional configuration is unknown. The location of $\beta$-receptors in the lungs suggests that

372 drug targeting is important for maximum therapeutic effect. For example, salbutamol requires a 373 more peripheral delivery to the medium and small airways to produce a therapeutic effect [16]. 374 Thus, particle size affects the lung deposition of an aerosol and influences the clinical 375 effectiveness. Zanen et al., (1996) reported that "in patients with mild to moderate asthma, 376 particles with an MMAD of approximately $3 \mu \mathrm{m}$ were more effective than larger particle size 
377 aerosol in producing bronchodilation since it has the best penetration and retention in the lungs

378 in the presence of airways narrowing" [39]. Breezhaler ${ }^{\circledR}$ was effective in producing particles with 379 an MMAD of around $3 \mu \mathrm{m}$ irrespective of the PIF, ACIM and Vin (Figure 3). ACIM and Vin have

380 almost a negligible effect on the MMAD whereas the indacaterol dispersion is more caused by 381 the PIF especially when combined with a fast and prolonged inhalation to increase the amount 382 of indacaterol reaching the distal stages of the impactor with more particles in the extrafine range $383(\leq 2 \mu \mathrm{m})$ with high tendency for peripheral deposition as shown at high PIF (85 L/min), ACIM (8 $384 \mathrm{~L} / \mathrm{s}^{2}$ ) and Vin (3 L) (Table 4). Particles with an MMAD $<3 \mu \mathrm{m}$ are important in targeting smaller 385 airways, and they found to be useful in the management of respiratory diseases $[40,41]$ 386

387 4. Conclusion

388 The Ex-vivo methodology on dose emission characteristics of indacaterol from Onbrez Breezhaler 389 using altered COPD patients' IPs provides an insight on how each inhalation manoeuvre 390 parameter contributes to the overall dose emission and its characteristics. PIF was the most 391 important parameter of the inhalation manoeuvre affecting the DD, FPD, EFPD, MMAD and RA. 392 Thus, dose de-aggregation, aerosol dispersion and drug retention in the device and capsule are 393 affected by the PIF. The ACIM affected mainly the DD and FPD, whereas the Vin has an effect on 394 the DD, FPD and RA. The ACIM and Vin have almost equally the same impact on the DD and FPD. 395 ACIM and Vin are involved more in mass transfer rather than aerosol dispersion. Combining all 396 optimal parameters of the inhalation manoeuvre in a single inhalation improves both the 397 quantity and the quality of the emitted dose. Thus, achieving a high peak flow faster with a 
398 prolonged inhalation would not only promote the highest emission of the dose, but also increases

399 the amount of the fine and extra fine drug particles being emitted.

400

401 Conflict of interest

402 The authors declare no conflicts of interest in this work.

403 Henry Chrystyn has no shares in any pharmaceutical companies. He has received sponsorship to 404 carry out studies, together with Board Membership, consultant agreements and honoraria for 405 presentation, from several pharmaceutical companies that market inhaled products. These

406 include Almirall, AstraZeneca, Boehringer Ingelheim, Chiesi, GlaxoSmithKline, Innovata Biomed, 407 Meda, Napp.

408 Pharmaceuticals, Mundipharma, NorPharma, Norvartis, Orion, Sanofi, Teva, Truddell Medical 409 International, UCB and Zentiva. Research sponsorship has also been received from grant 410 awarding bodies (EPSRC and MRC). He is the owner of Inhalation Consultancy Ltd. He is also a 411 consultant of Research in Real Life, which is subcontracted by Observational and Pragmatic 412 Research Institute Pte Ltd. 


\section{Reference}

[1] H. Chrystyn, Effects of device design on patient compliance : Comparing the same drug in different devices., in: RDD Eur. 2009, 2009: pp. 105-116.

http://www.rddonline.com/pub/article.php?ArticlelD=1362 (accessed November 26, 2016).

[2] N. Islam, M.J. Cleary, Developing an efficient and reliable dry powder inhaler for pulmonary drug delivery - A review for multidisciplinary researchers, Med. Eng. Phys. (2012). https://doi.org/10.1016/j.medengphy.2011.12.025.

[3] M. Molimard, C. Raherison, S. Lignot, F. Depont, A. Abouelfath, N. Moore, Assessment of handling of inhaler devices in real life: An observational study in 3811 patients in primary care, J. Aerosol Med. Depos. Clear. Eff. Lung. (2003). https://doi.org/10.1089/089426803769017613.

[4] T. Peng, S. Lin, B. Niu, X. Wang, Y. Huang, X. Zhang, G. Li, X. Pan, C. Wu, Influence of physical properties of carrier on the performance of dry powder inhalers, Acta Pharm. Sin. B. 6 (2016) 308-318. https://doi.org/10.1016/J.APSB.2016.03.011.

[5] S.P. Newman, W.W. Busse, Evolution of dry powder inhaler design, formulation, and performance, Respir. Med. 96 (2002) 293-304. https://doi.org/10.1053/rmed.2001.1276.

[6] H. Chrystyn, D. Price, Not all asthma inhalers are the same: Factors to consider when prescribing an inhaler, Prim. Care Respir. J. 18 (2009) 243-249. https://doi.org/10.4104/pcrj.2009.00029.

[7] J.P. Mitchell, What the pulmonary specialist should know about the new inhalation therapies, Eur. Respir. J. 39 (2012) 1054-1055. 
https://doi.org/10.1183/09031936.00210911.

[8] M. Abadelah, H. Chrystyn, H. Larhrib, Use of inspiratory profiles from patients with chronic obstructive pulmonary disease (COPD) to investigate drug delivery uniformity and aerodynamic dose emission of indacaterol from a capsule based dry powder inhaler, Eur. J. Pharm. Sci. (2019). https://doi.org/10.1016/j.ejps.2019.04.018.

[9] G. Bagherisadeghi, E.H. Larhrib, H. Chrystyn, Real life dose emission characterization using COPD patient inhalation profiles when they inhaled using a fixed dose combination (FDC) of the medium strength Symbicort ${ }^{\circledR}$ Turbuhaler $^{\circledast}$, Int. J. Pharm. 522 (2017) 137146. https://doi.org/10.1016/J.IJPHARM.2017.02.057.

[10] W. Azouz, P. Chetcuti, H.S.R. Hosker, D. Saralaya, J. Stephenson, H. Chrystyn, The inhalation characteristics of patients when they use different dry powder inhalers, J. Aerosol Med. Pulm. Drug Deliv. 28 (2015) 35-42. https://doi.org/10.1089/jamp.2013.1119.

[11] W. Azouz, P. Chetcuti, H. Hosker, D. Saralaya, H. Chrystyn, Inhalation characteristics of asthma patients, COPD patients and healthy volunteers with the Spiromax ${ }^{\circledR}$ and Turbuhaler $^{\circledR}$ devices: A randomised, cross-over study, BMC Pulm. Med. 15 (2015). https://doi.org/10.1186/s12890-015-0043-x.

[12] R.A.M. Al-Showair, W.Y. Tarsin, K.H. Assi, S.B. Pearson, H. Chrystyn, Can all patients with COPD use the correct inhalation flow with all inhalers and does training help?, Respir. Med. 101 (2007) 2395-2401.

[13] F. Lavorini, M. Pistolesi, O.S. Usmani, Recent advances in capsule-based dry powder inhaler technology, Multidiscip. Respir. Med. (2017). https://doi.org/10.1186/s40248- 
017-0092-5.

463

464

465

466

467

468

469

470

471

472

473

474

475

476

477

478

479

480

481

482

483

[14] M.L. Everard, S.G. Devadason, P.N. Le Souëf, Flow early in the inspiratory manoeuvre affects the aerosol particle size distribution from a Turbuhaler, Respir. Med. (1997). https://doi.org/10.1016/S0954-6111(97)90009-3.

[15] H. Chrystyn, G. Safioti, J.R. Keegstra, G. Gopalan, Effect of inhalation profile and throat geometry on predicted lung deposition of budesonide and formoterol (BF) in COPD: An in-vitro comparison of Spiromax with Turbuhaler, Int. J. Pharm. 491 (2015) 268-276. https://doi.org/10.1016/j.ijpharm.2015.05.076.

[16] N.R. Labiris, M.B. Dolovich, Pulmonary drug delivery. Part II: The role of inhalant delivery devices and drug formulations in therapeutic effectiveness of aerosolized medications, Br. J. Clin. Pharmacol. 56 (2003) 600-612. https://doi.org/10.1046/j.13652125.2003.01893.x.

[17] W.J. Vaughan, B.E. Vaughan, Deposition of inhaled particles in lungs, Nature. 221 (1969) 661-662. https://doi.org/10.1038/221661b0.

[18] M. Abadelah, H. Chrystyn, G. Bagherisadeghi, G. Abdalla, H. Larhrib, Study of the Emitted Dose After Two Separate Inhalations at Different Inhalation Flow Rates and Volumes and an Assessment of Aerodynamic Characteristics of Indacaterol Onbrez Breezhaler ${ }^{\circledR} 150$ and 300 g, AAPS PharmSciTech. (2017). https://doi.org/10.1208/s12249-017-0841-y.

[19] R.W. Dal Negro, Dry powder inhalers and the right things to remember: A concept review, Multidiscip. Respir. Med. 10 (2015) 1. https://doi.org/10.1186/s40248-015-00125.

[20] M.M.A. Abadelah, Effect of Inhalation Manoeuvre Parameters In- Vitro and Ex-Vivo on 
the Dose Emission and the Aerodynamic Characteristics of Formoterol and Indacaterol from Marketed Dry Powder Inhalers, 2017. http://eprints.hud.ac.uk/id/eprint/34508/ (accessed October 10, 2020).

[21] E. V. Hillyer, D.B. Price, H. Chrystyn, R.J. Martin, E. Israel, W.M.C. van Aalderen, A. Papi, O.S. Usmani, N. Roche, Harmonizing the Nomenclature for Therapeutic Aerosol Particle Size: A Proposal, J. Aerosol Med. Pulm. Drug Deliv. (2018). https://doi.org/10.1089/jamp.2017.1396.

[22] R. Pavkov, S. Mueller, K. Fiebich, D. Singh, F. Stowasser, G. Pignatelli, B. Walter, D. Ziegler, M. Dalvi, J. Dederichs, I. Rietveld, Characteristics of a capsule based dry powder inhaler for the delivery of indacaterol, Curr. Med. Res. Opin. 26 (2010) 2527-2533. https://doi.org/10.1185/03007995.2010.518916.

[23] K.R. Chapman, C.M. Fogarty, C. Peckitt, C. Lassen, D. Jadayel, J. Dederichs, M. Dalvi, B. Kramer, Delivery characteristics and patients' handling of two single-dose dry-powder inhalers used in COPD, Int. J. COPD. 6 (2011) 353-363. https://doi.org/10.2147/COPD.S18529.

[24] P. Colthorpe, T. Voshaar, T. Kieckbusch, E. Cuoghi, J. Jauernig, Delivery characteristics of a low-resistance dry-powder inhaler used to deliver the long-acting muscarinic antagonist glycopyrronium, J. Drug Assess. 2 (2013) 11-16. https://doi.org/10.3109/21556660.2013.766197.

[25] P. Altman, L. Wehbe, J. Dederichs, T. Guerin, B. Ament, M.C. Moronta, A.V. Pino, P. Goyal, Comparison of peak inspiratory flow rate via the Breezhaler ${ }^{\circledR}$, Ellipta ${ }^{\circledR}$ and HandiHaler ${ }^{\circledR}$ dry powder inhalers in patients with moderate to very severe COPD: A 
randomized cross-over trial, BMC Pulm. Med. (2018). https://doi.org/10.1186/s12890018-0662-0.

508
[26] A.M. Ciciliani, P. Langguth, H. Wachtel, In vitro dose comparison of respimat ${ }^{\circledR}$ inhaler $^{2}$ with dry powder inhalers for COPD maintenance therapy, Int. J. COPD. (2017). https://doi.org/10.2147/COPD.S115886.

[27] S. Ghosh, J.A. Ohar, M.B. Drummond, Peak Inspiratory Flow Rate in Chronic Obstructive Pulmonary Disease: Implications for Dry Powder Inhalers, J. Aerosol Med. Pulm. Drug Deliv. (2017). https://doi.org/10.1089/jamp.2017.1416.

[28] H. Chrystyn, Is inhalation rate important for a dry powder inhaler? Using the In-Check Dial to identify these rates, Respir. Med. 97 (2003) 181-187. https://doi.org/10.1053/rmed.2003.1351.

[29] P. Haidl, S. Heindl, K. Siemon, M. Bernacka, R.M. Cloes, Inhalation device requirements for patients' inhalation maneuvers, Respir. Med. 118 (2016). https://doi.org/10.1016/j.rmed.2016.07.013.

[30] A.R. Clark, A.M. Hollingworth, The Relationship Between Powder Inhaler Resistance and Peak Inspiratory Conditions in Healthy Volunteers - Implications for In Vitro Testing, J. Aerosol Med. Depos. Clear. Eff. Lung. 6 (1993) 99-110. https://doi.org/10.1089/jam.1993.6.99.

[31] J.P. De Koning, T.W. Van Der Mark, P.M.J. Coenegracht, T.F.J. Tromp, H.W. Frijlink, Effect of an external resistance to airflow on the inspiratory flow curve, Int. J. Pharm. (2002). https://doi.org/10.1016/S0378-5173(01)00969-3.

[32] J. Haughney, D. Price, N.C. Barnes, J.C. Virchow, N. Roche, H. Chrystyn, Choosing inhaler 
devices for people with asthma: Current knowledge and outstanding research needs, Respir. Med. CME. 3 (2010) 125-131. https://doi.org/10.1016/j.rmedc.2010.10.004.

[33] R. Sechaud, M. Sudershan, S. Perry, H. Hara, Efficient deposition and sustained lung concentrations of NVA237 after inhalation via the Breezhaler ${ }^{\circledR}$ device in man, Eur. Respir. J. 40 (2012) P4839. https://erj.ersjournals.com/content/40/Suppl_56/P4839.short (accessed October 10, 2020).

[34] M.E.A.C. Broeders, J. Molema, W.C.J. Hop, H.T.M. Folgering, Inhalation Profiles in Asthmatics and COPD Patients: Reproducibility and Effect of Instruction, J. Aerosol Med. 16 (2003) 131-141. https://doi.org/10.1089/089426803321919898.

[35] M. Copley, M. Smurthwaite, D.L. Roberts, J.P. Mitchell, Revised internal volumes of cascade impactors for those provided by Mitchell and Nagel, J. Aerosol Med. Depos. Clear. Eff. Lung. 18 (2005) 364-366. https://doi.org/10.1089/jam.2005.18.364.

[36] H. Mohammed, D.L. Roberts, M. Copley, M. Hammond, S.C. Nichols, J.P. Mitchell, Effect of Sampling Volume on Dry Powder Inhaler (DPI)-Emitted Aerosol Aerodynamic Particle Size Distributions (APSDs) Measured by the Next-Generation Pharmaceutical Impactor (NGI) and the Andersen Eight-Stage Cascade Impactor (ACI), AAPS PharmSciTech. 13 (2012) 875-882. https://doi.org/10.1208/s12249-012-9797-0.

[37] H. Mohammed, J. Arp, F. Chambers, M. Copley, V. Glaab, M. Hammond, D. Solomon, K. Bradford, T. Russell, Y. Sizer, S.C. Nichols, D.L. Roberts, C. Shelton, R. Greguletz, J.P. Mitchell, Investigation of Dry Powder Inhaler (DPI) resistance and aerosol dispersion timing on emitted aerosol aerodynamic particle sizing by multistage cascade impactor when sampled volume is reduced from compendial value of $4 \mathrm{~L}$, AAPS PharmSciTech. 
(2014). https://doi.org/10.1208/s12249-014-0111-1.

551

552

553

554

555

556

557

558

559

560

561

562

563

564

565

566

567

568

569

570

571
[38] M. Abadelah, F. Hazim, H. Chrystyn, G. Bagherisadeghi, H. Rahmoune, H. Larhrib, Effect of maximum inhalation flow and inhaled volume on formoterol drug deposition in-vitro from an Easyhaler ${ }^{\circledR}$ dry powder inhaler, Eur. J. Pharm. Sci. 104 (2017).

https://doi.org/10.1016/j.ejps.2017.03.035.

[39] P. Zanen, L.T. Go, J.W.J. Lammers, Optimal particle size for $\beta 2$ agonist and anticholinergic aerosols in patients with severe airflow obstruction, Thorax. 51 (1996) 977-980. https://doi.org/10.1136/thx.51.10.977.

[40] A.H. De Boer, D. Gjaltema, P. Hagedoorn, H.W. Frijlink, Can “extrafine” dry powder aerosols improve lung deposition?, Eur. J. Pharm. Biopharm. 96 (2015). https://doi.org/10.1016/j.ejpb.2015.07.016.

[41] N. Scichilone, Asthma Control: The Right Inhaler for the Right Patient, Adv. Ther. (2015). https://doi.org/10.1007/s12325-015-0201-9. 


\section{List of Figures' Caption}

573

574 Figure 1: Schematic diagram of the experimental set-up of the Andersen Cascade

575 Impactor (ACl) with Breath simulator (BRS).

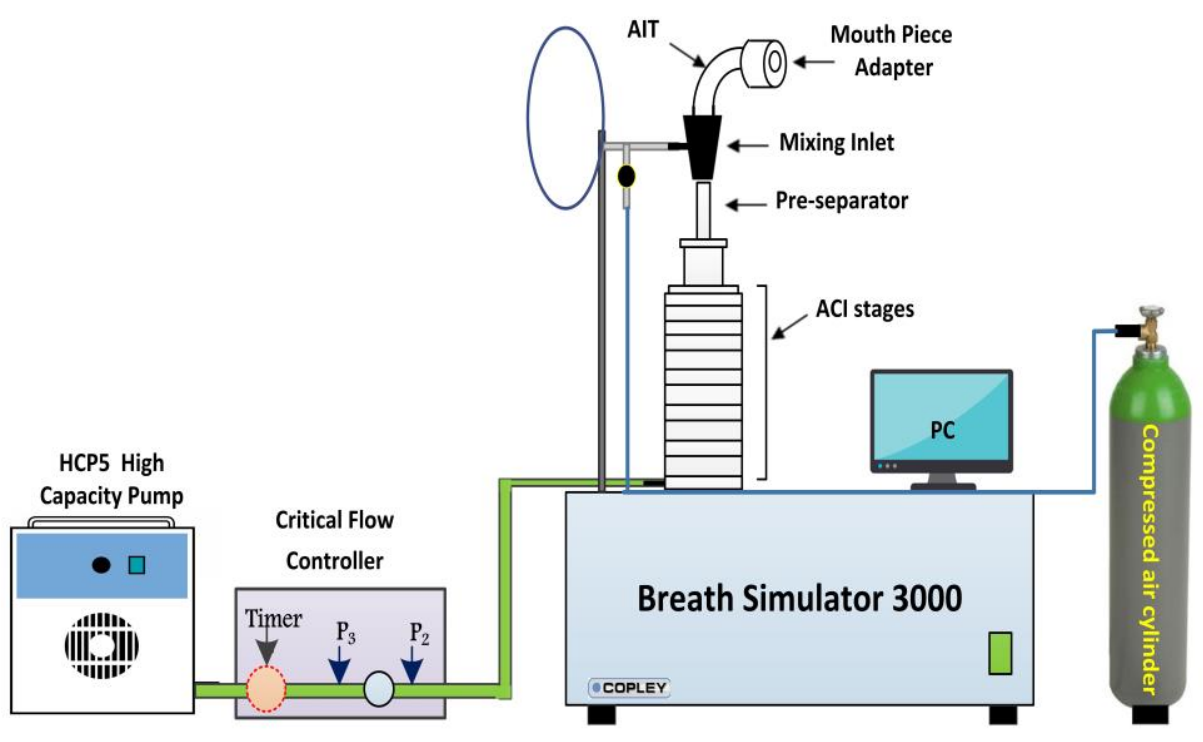


580 Figure 2: Mean (SD) Fine particle dose (FPD) represented as percentage of the 581 nominal dose $\mu \mathrm{g}$ for each inhalation profile $(\mathrm{n}=3)$

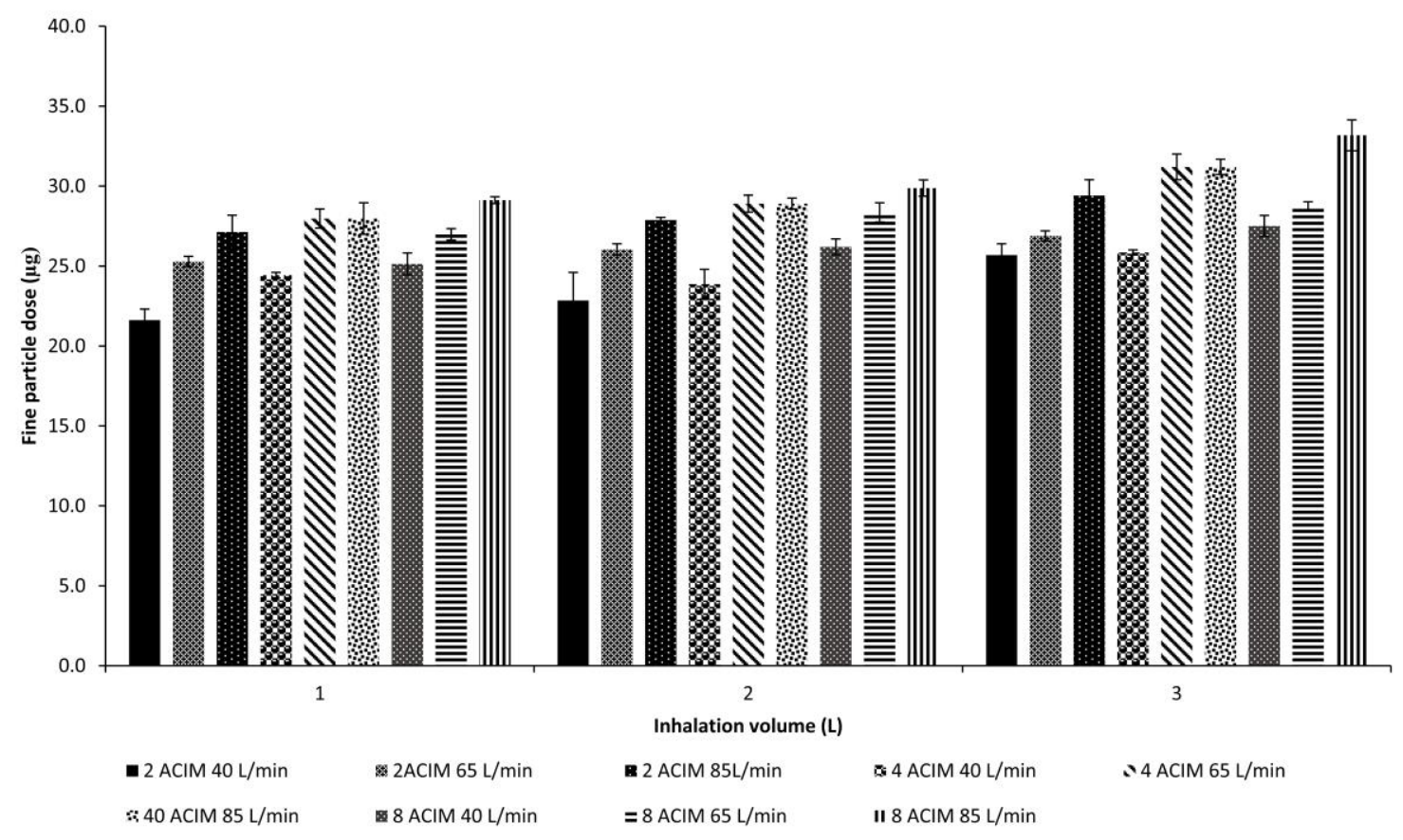


588 Figure 3: Mean (SD) Mass median aerodynamic diameter (MMAD) for each 589 inhalation profile

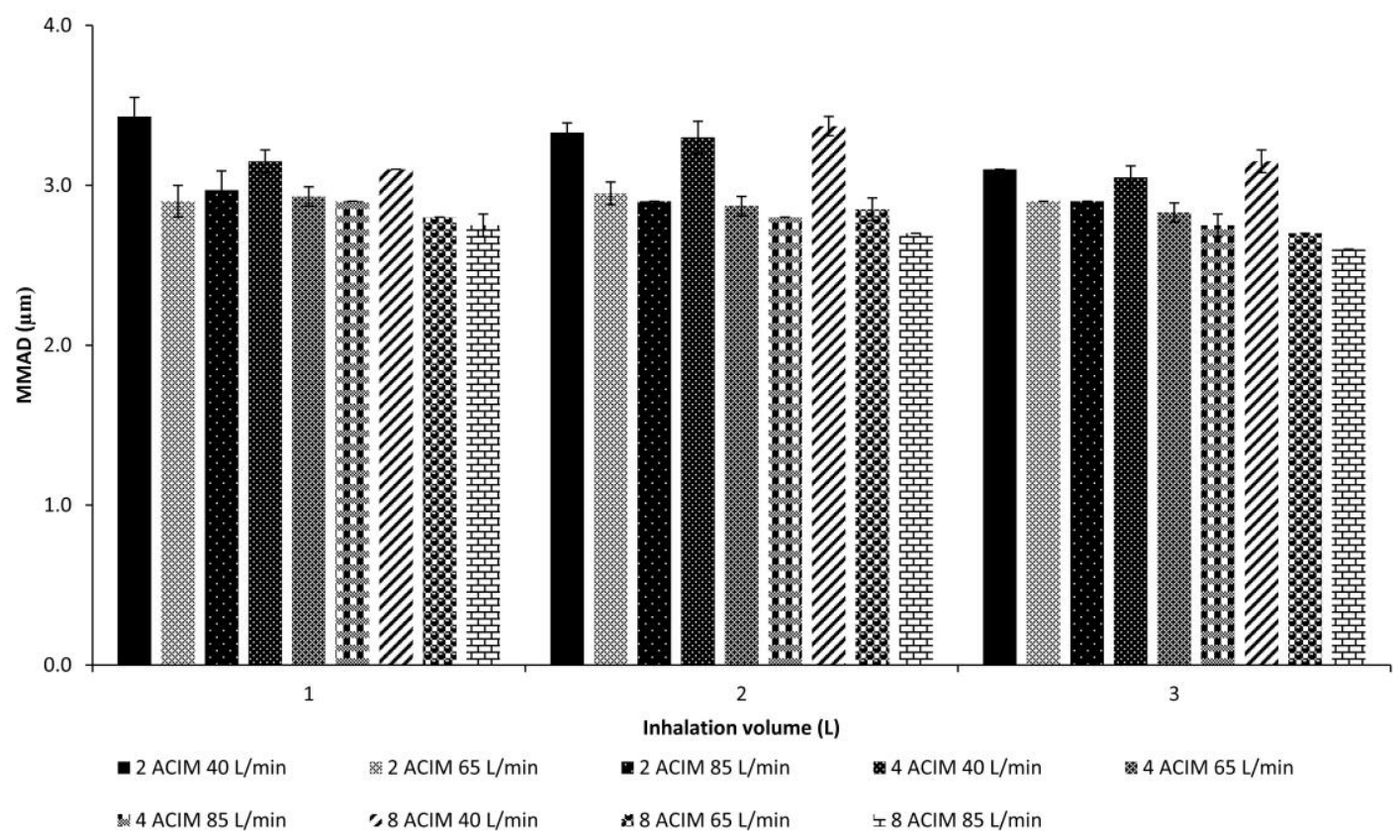



for all the inhalation profiles, represented as percentage of the nominal dose

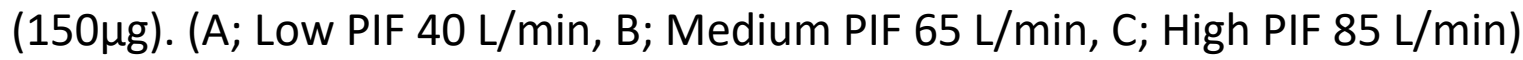

A

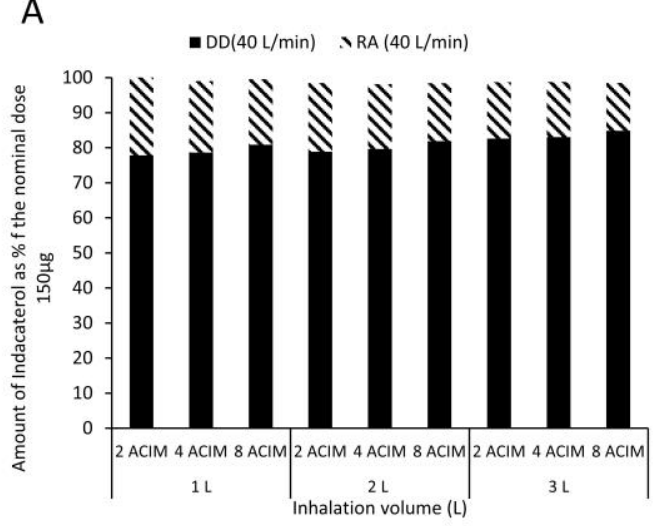

B

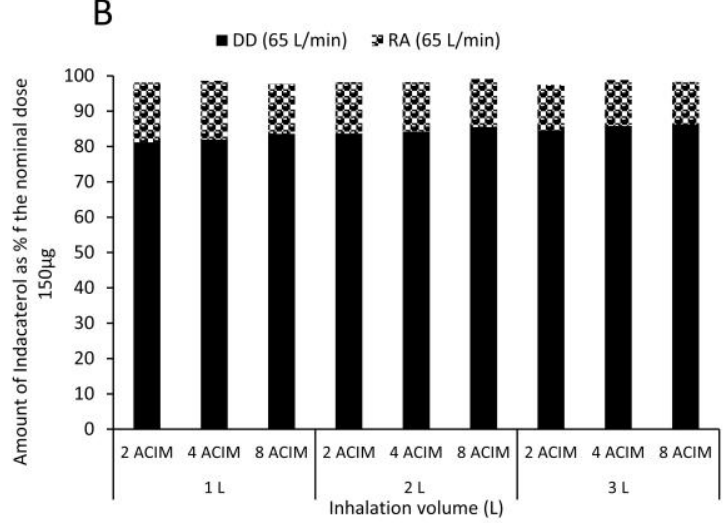

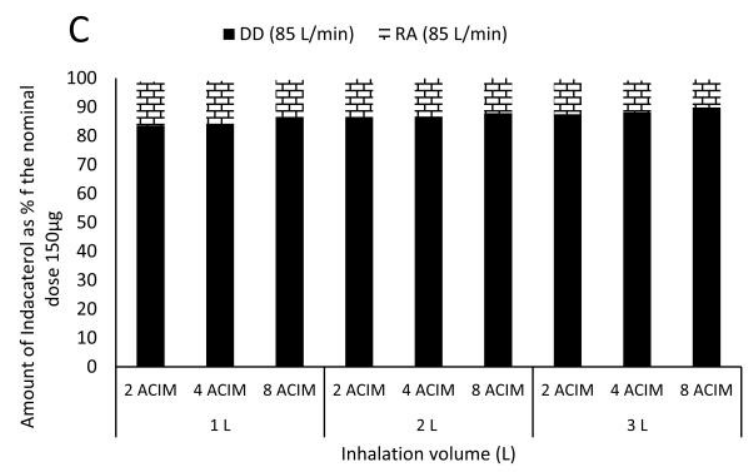


606

\begin{tabular}{|l|l|}
\hline Column & Phenomenex RP-Kinetex $185 \mu \mathrm{m}, 250 \mathrm{~mm} 4.6 \mathrm{~mm}$ \\
\hline $\begin{array}{l}\text { Column } \\
\text { temperature }\end{array}$ & $40{ }^{\circ} \mathrm{C}$ \\
\hline Mobile phase & $\begin{array}{l}\text { Methanol / } 25 \mathrm{mM} \text { Potassium hydrogen orthophosphate, adjusted to } \\
\mathrm{pH} 2.5 \text { using orthophosphoric acid } 60: 40 \% \mathrm{v} / \mathrm{v}\end{array}$ \\
\hline Flow rate & $1 \mathrm{~mL} / \mathrm{min}$ \\
\hline Injection volume & $20 \mu \mathrm{L}$ \\
\hline Detection, UV & $259 \mathrm{~nm}$ \\
\hline Run Time & $6 \mathrm{~min}$ \\
\hline Internal standard & Dexamethasone $1 \mu \mathrm{g} / \mathrm{mL}$ \\
\hline
\end{tabular}

607

608

609

610

611

612

613

614

615

616 
Table 2: Mean (SD) indacaterol APSD for low PIF (40 L/min) profiles $(n=3)$ using 3 doses for each

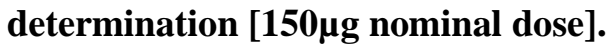

\begin{tabular}{|c|c|c|c|}
\hline & \multicolumn{3}{|c|}{ Vin 1L } \\
\hline & ACIM $\sim 2.0 \mathrm{~L} / \mathrm{s}^{2}$ & ACIM $\sim 4.0 \mathrm{~L} / \mathrm{s}^{2}$ & ACIM $\sim 8.0 \mathrm{~L} / \mathrm{s}^{2}$ \\
\hline FPD $(\mu \mathrm{g})$ & $29.4(0.7)$ & $31.6(0.2)$ & $34.7(0.7)$ \\
\hline$\% \mathrm{FPF}$ & $25.9(3.2)$ & $27.6(1.9)$ & $28.8(2.3)$ \\
\hline LPM $(\mu g)$ & $70.2(1.6)$ & $68.3(1.2)$ & $72.8(1.4)$ \\
\hline EFPD $(\mu \mathrm{g})$ & $19.7(1.1)$ & $23.8(1.0)$ & $25.2(0.3)$ \\
\hline $\operatorname{MMAD}(\mu \mathrm{m})$ & $3.4(0.1)$ & $3.2(0.1)$ & $3.1(0.0)$ \\
\hline \multirow[t]{3}{*}{ GSD } & $1.8(0.0)$ & $1.8(0.0)$ & $1.9(0.0)$ \\
\hline & \multicolumn{3}{|c|}{ Vin $\sim 2 L$} \\
\hline & $2.0 \mathrm{~L} / \mathrm{s}^{2}$ & $4.0 \mathrm{~L} / \mathrm{s}^{2}$ & $8.0 \mathrm{~L} / \mathrm{s}^{2}$ \\
\hline FPD $(\mu \mathrm{g})$ & $33.3(1.8)$ & $35.8(1.9)$ & $38.3(0.5)$ \\
\hline$\% \mathrm{FPF}$ & $28.3(0.8)$ & $30.3(3.0)$ & $31.4(1.2)$ \\
\hline LPM $(\mu \mathrm{g})$ & $70.4(1.9)$ & $69.7(2.8)$ & $70.5(2.5)$ \\
\hline EFPD $(\mu \mathrm{g})$ & $21.1(0.1)$ & $21.8(0.9)$ & $23.6(0.4)$ \\
\hline MMAD $(\mu \mathrm{m})$ & $3.3(0.1)$ & $3.3(0.1)$ & $3.4(0.1)$ \\
\hline \multirow[t]{3}{*}{ GSD } & $1.8(0.1)$ & $1.8(0.1)$ & $1.8(0.0)$ \\
\hline & \multicolumn{3}{|c|}{ Vin 3L } \\
\hline & $2.0 \mathrm{~L} / \mathrm{s}^{2}$ & $4.0 \mathrm{~L} / \mathrm{s}^{2}$ & $8.0 \mathrm{~L} / \mathrm{s}^{2}$ \\
\hline FPD $(\mu \mathrm{g})$ & $36.5(0.7)$ & $38.8(1.1)$ & $40.3(0.7)$ \\
\hline$\% \mathrm{FPF}$ & $30.3(1.2)$ & $31.9(3.0)$ & $32.7(0.9)$ \\
\hline LPM $(\mu \mathrm{g})$ & $70.7(2.8)$ & $71.4(2.5)$ & $71.8(3.2)$ \\
\hline EFPD $(\mu \mathrm{g})$ & $25.7(0.2)$ & $26.6(0.3)$ & $26.8(0.5)$ \\
\hline MMAD $(\mu \mathrm{m})$ & $3.1(0.0)$ & $3.1(0.1)$ & $3.2(0.1)$ \\
\hline GSD & $1.9(0.0)$ & $2.0(0.0)$ & $1.9(0.1)$ \\
\hline
\end{tabular}
FPD, Fine particle dose; FPF, Fine particle fraction; LPM, Large particle mass; EFPD, extra fine particle dose; MMAD, Mass median aerodynamic diameter; GSD, Geometric standard deviation

621

622

623

624

625

626 
Table 3: Mean (SD) indacaterol APSD for medium PIF $(65 \mathrm{~L} / \mathrm{min})$ profiles $(\mathrm{n}=3)$ using 3 doses for each determination [150 $\mu \mathrm{g}$ nominal dose].

630

\begin{tabular}{|c|c|c|c|}
\hline & \multicolumn{3}{|c|}{ Vin $\sim 1 \mathrm{~L}$} \\
\hline & ACIM $\sim 2.0 \mathrm{~L} / \mathrm{s}^{2}$ & ACIM $\sim 4.0 \mathrm{~L} / \mathrm{s}^{2}$ & $\mathrm{ACIM} \sim 8.0 \mathrm{~L} / \mathrm{s}^{2}$ \\
\hline FPD $(\mu \mathrm{g})$ & $37.9(1.3)$ & $38.1(0.6)$ & $40.5(0.4)$ \\
\hline$\% \mathrm{FPF}$ & $32.7(3.0)$ & $32.9(1.2)$ & $32.9(3.2)$ \\
\hline LPM $(\mu \mathrm{g})$ & $67.9(4.4)$ & $66.8(0.9)$ & $69.4(2.2)$ \\
\hline EFPD $(\mu \mathrm{g})$ & $31.04(0.8)$ & $30.40(0.2)$ & $32.89(0.7)$ \\
\hline MMAD $(\mu \mathrm{m})$ & $2.9(0.1)$ & $2.9(0.1)$ & $2.8(0.0)$ \\
\hline \multirow[t]{3}{*}{ GSD } & $2.0(0.0)$ & $1.9(0.1)$ & $2.1(0.0)$ \\
\hline & \multicolumn{3}{|c|}{ Vin $\sim 2 L$} \\
\hline & $2.0 \mathrm{~L} / \mathrm{s}^{2}$ & $4.0 \mathrm{~L} / \mathrm{s}^{2}$ & $8.0 \mathrm{~L} / \mathrm{s}^{2}$ \\
\hline FPD $(\mu \mathrm{g})$ & $39.0(0.4)$ & $39.9(0.5)$ & $42.5(1.6)$ \\
\hline$\% \mathrm{FPF}$ & $33.0(2.2)$ & $33.5(0.8)$ & $34.2(1.7)$ \\
\hline LPM $(\mu g)$ & $73.6(0.9)$ & $68.7(1.6)$ & $70.7(2.3)$ \\
\hline EFPD $(\mu \mathrm{g})$ & $27.85(1.3)$ & $32.11(0.6)$ & $34.85(1.0)$ \\
\hline MMAD $(\mu \mathrm{m})$ & $3.0(0.1)$ & $2.9(0.1)$ & $2.9(0.1)$ \\
\hline \multirow[t]{3}{*}{ GSD } & $2.2(0.1)$ & $2.0(0.0)$ & $2.0(0.0)$ \\
\hline & \multicolumn{3}{|c|}{ Vin $\sim 3 L$} \\
\hline & $2.0 \mathrm{~L} / \mathrm{s}^{2}$ & $4.0 \mathrm{~L} / \mathrm{s}^{2}$ & $8.0 \mathrm{~L} / \mathrm{s}^{2}$ \\
\hline FPD $(\mu g)$ & $40.3(0.3)$ & $41.7(0.8)$ & $43(0.3)$ \\
\hline$\% \mathrm{FPF}$ & $33.2(2.3)$ & $34.0(1.9)$ & $34.2(3.2)$ \\
\hline LPM $(\mu \mathrm{g})$ & $66.1(1.2)$ & $70.6(2.8)$ & $72.4(2.2)$ \\
\hline EFPD $(\mu \mathrm{g})$ & $32.98(0.9)$ & $33.88(0.6)$ & $36.09(0.9)$ \\
\hline $\operatorname{MMAD}(\mu \mathrm{m})$ & $2.9(0.0)$ & $2.8(0.1)$ & $2.7(0.0)$ \\
\hline GSD & $2.0(0.0)$ & $1.9(0.0)$ & $2.1(0.1)$ \\
\hline
\end{tabular}

631 FPD, Fine particle dose; FPF, Fine particle fraction; LPM, Large particle mass; EFPD, extra fine particle dose; 
640

\begin{tabular}{|c|c|c|c|}
\hline & \multicolumn{3}{|c|}{ Vin $\sim 1 \mathrm{~L}$} \\
\hline & ACIM $\sim 2.0 \mathrm{~L} / \mathrm{s}^{2}$ & ACIM 4.0 L/s $/ \mathrm{s}^{2}$ & ACIM $\sim 8.0 \mathrm{~L} / \mathrm{s}^{2}$ \\
\hline FPD $(\mu \mathrm{g})$ & $40.7(1.1)$ & $42.0(1.0)$ & $43.7(0.2)$ \\
\hline$\% \mathrm{FPF}$ & $34.3(1.1)$ & $35.4(0.6)$ & $35.8(1.9)$ \\
\hline LPM $(\mu \mathrm{g})$ & $67.9(2.7)$ & $71.0(1.9)$ & $73.1(2.9)$ \\
\hline EFPD $(\mu \mathrm{g})$ & $33.26(0.5)$ & $30.85(0.3)$ & $32.91(1.2)$ \\
\hline MMAD $(\mu \mathrm{m})$ & $3.0(0.1)$ & $2.9(0.0)$ & $2.8(0.1)$ \\
\hline \multirow[t]{3}{*}{ GSD } & $2.0(0.1)$ & $2.0(0.0)$ & $2.1(0.1)$ \\
\hline & \multicolumn{3}{|c|}{ Vin 2L } \\
\hline & $2.0 \mathrm{~L} / \mathrm{s}^{2}$ & $4.0 \mathrm{~L} / \mathrm{s}^{2}$ & $8.0 \mathrm{~L} / \mathrm{s}^{2}$ \\
\hline FPD $(\mu \mathrm{g})$ & $41.8(0.2)$ & $43.4(0.3)$ & $44.8(1.5)$ \\
\hline$\% \mathrm{FPF}$ & $34.7(0.5)$ & $35.8(1.8)$ & $36.2(0.5)$ \\
\hline LPM $(\mu \mathrm{g})$ & $72.4(1.6)$ & $72.6(1.0)$ & $74.1(3.5)$ \\
\hline EFPD $(\mu \mathrm{g})$ & $30.35(0.8)$ & $32.32(0.4)$ & $34.44(0.2)$ \\
\hline MMAD $(\mu \mathrm{m})$ & $2.9(0.0)$ & $2.8(0.0)$ & $2.7(0.0)$ \\
\hline \multirow[t]{3}{*}{ GSD } & $2.1(0.0)$ & $2.0(0.0)$ & $2.0(0.0)$ \\
\hline & \multicolumn{3}{|c|}{ Vin $\sim 3 L$} \\
\hline & $2.0 \mathrm{~L} / \mathrm{s}^{2}$ & $4.0 \mathrm{~L} / \mathrm{s}^{2}$ & $8.0 \mathrm{~L} / \mathrm{s}^{2}$ \\
\hline FPD $(\mu g)$ & $44.1(1.0)$ & $46.8(0.5)$ & $49.8(1.0)$ \\
\hline$\% \mathrm{FPF}$ & $35.9(1.7)$ & $37.8(1.3)$ & $38.7(2.0)$ \\
\hline LPM $(\mu \mathrm{g})$ & $73.5(2.4)$ & $71.8(3.0)$ & $73.0(2.6)$ \\
\hline EFPD $(\mu \mathrm{g})$ & $32.34(0.8)$ & $35.03(0.2)$ & $39.16(0.2)$ \\
\hline MMAD $(\mu \mathrm{m})$ & $2.9(0.0)$ & $2.8(0.1)$ & $2.6(0.0)$ \\
\hline GSD & $2.0(0.0)$ & $2.0(0.0)$ & $2.1(0.0)$ \\
\hline
\end{tabular}

641

642

FPD, Fine particle dose; FPF, Fine particle fraction; LPM, Large particle mass; EFPD, extra fine particle dose; MMAD, Mass median aerodynamic diameter; GSD, Geometric standard deviation

643

644

645

646

647 
Table 5: Mean (SD) indacaterol delivered dose and residual amounts (in $\mu \mathrm{g}$ ) for all profiles using 1 dose for each determination ( $n=3$ separate determinations). [150 $\mu \mathrm{g}$ nominal dose].

651

\begin{tabular}{|c|c|c|c|}
\hline & $40 \mathrm{~L} / \mathrm{min}$ & $65 \mathrm{~L} / \mathrm{min}$ & $85 \mathrm{~L} / \mathrm{min}$ \\
\hline \multicolumn{4}{|c|}{$1 \mathrm{~L}-2 \mathrm{~L} / \mathrm{s}^{2}$} \\
\hline DD $(\mu \mathrm{g})$ & $116.80(1.25)$ & $121.84(0.11)$ & $125.41(0.73)$ \\
\hline $\mathbf{R A}(\boldsymbol{\mu g})$ & $33.51(1.00)$ & $25.36(1.04)$ & $22.76(0.54)$ \\
\hline TRD $(\mu g)$ & $150.32(0.25)$ & $147.21(0.93)$ & $148.17(0.19)$ \\
\hline \multicolumn{4}{|c|}{$1 \mathrm{~L}-4 \mathrm{~L} / \mathrm{s}^{2}$} \\
\hline $\mathrm{DD}(\boldsymbol{\mu g})$ & $117.96(2.08)$ & $122.99(3.50)$ & $126.27(3.50)$ \\
\hline $\mathbf{R A}(\boldsymbol{\mu g})$ & $30.58(0.73)$ & $24.92(3.18)$ & $22.32(3.71)$ \\
\hline TRD $(\mu \mathrm{g})$ & $148.54(1.35)$ & $147.92(0.32)$ & $148.59(0.21)$ \\
\hline \multicolumn{4}{|c|}{$1 \mathrm{~L}-8 \mathrm{~L} / \mathrm{s}^{2}$} \\
\hline DD $(\mu \mathrm{g})$ & $121.31(0.16)$ & $125.39(1.06)$ & $129.40(1.68)$ \\
\hline $\mathbf{R A}(\boldsymbol{\mu g})$ & $27.98(2.77)$ & $21.19(1.49)$ & $19.70(0.62)$ \\
\hline TRD $(\mu g)$ & $149.29(2.93)$ & $146.58(0.43)$ & $149.11(1.06)$ \\
\hline \multicolumn{4}{|c|}{$2 \mathrm{~L}-2 \mathrm{~L} / \mathrm{s}^{2}$} \\
\hline DD $(\mu \mathrm{g})$ & $118.32(1.26)$ & $12 \mu 0(0.05)$ & $129.37(2.99)$ \\
\hline $\mathbf{R A}(\boldsymbol{\mu g})$ & $29.38(4.48)$ & $21.84(1.90)$ & $20.24(1.74)$ \\
\hline TRD $(\mu g)$ & $147.70(1.22)$ & $147.34(1.85)$ & $149.61(1.25)$ \\
\hline \multicolumn{4}{|c|}{$2 \mathrm{~L}-4 \mathrm{~L} / \mathrm{s}^{2}$} \\
\hline DD $(\mu \mathrm{g})$ & $119.48(0.28)$ & $126.19(2.38)$ & $130.06(1.12)$ \\
\hline RA( $(\mu \mathrm{g})$ & $27.74(0.53)$ & $21.16(0.35)$ & $19.88(0.85)$ \\
\hline TRD( $\mu g)$ & $147.22(0.81)$ & $147.35(2.73)$ & $151.22(1.47)$ \\
\hline \multicolumn{4}{|c|}{$2 \mathrm{~L}-8 \mathrm{~L} / \mathrm{s}^{2}$} \\
\hline $\mathrm{DD}(\boldsymbol{\mu g})$ & $122.81(0.79)$ & $128.26(1.11)$ & $131.83(1.95)$ \\
\hline $\mathbf{R A}(\boldsymbol{\mu g})$ & $24.75(1.39)$ & $20.42(1.19)$ & $19.72(0.98)$ \\
\hline TRD( $\mu g)$ & $147.56(0.61)$ & $148.68(0.08)$ & $151.55(0.76)$ \\
\hline \multicolumn{4}{|c|}{$3 \mathrm{~L}-2 \mathrm{~L} / \mathrm{s}^{2}$} \\
\hline DD $(\mu \mathrm{g})$ & $123.98(0.44)$ & $126.83(1.47)$ & $131.29(0.64)$ \\
\hline $\mathbf{R A}(\mu \mathrm{g})$ & $24.05(1.01)$ & $19.31(0.77)$ & $18.20(0.80)$ \\
\hline TRD $(\mu g)$ & $148.03(0.57)$ & $146.14(0.69)$ & $149.49(0.17)$ \\
\hline \multicolumn{4}{|c|}{$3 \mathrm{~L}-4 \mathrm{~L} / \mathrm{s}^{2}$} \\
\hline $\mathrm{DD}(\boldsymbol{\mu g})$ & $124.61(2.65)$ & $128.73(1.36)$ & $132.30(1.78)$ \\
\hline $\mathbf{R A}(\boldsymbol{\mu g})$ & $23.53(2.00)$ & $19.49(0.55)$ & $16.51(1.56)$ \\
\hline TRD( $\mu g)$ & $148.14(0.65)$ & $148.22(1.91)$ & $148.82(0.22)$ \\
\hline \multicolumn{4}{|c|}{$3 \mathrm{~L}-8 \mathrm{~L} / \mathrm{s}^{2}$} \\
\hline DD $(\mu \mathrm{g})$ & $127.30(1.35)$ & $129.47(0.31)$ & $134.83(1.58)$ \\
\hline $\mathbf{R A}(\boldsymbol{\mu g})$ & $20.43(1.42)$ & $17.93(0.20)$ & $14.58(2.44)$ \\
\hline TRD $(\mu g)$ & $147.73(4.77)$ & $147.40(0.51)$ & $149.41(0.86)$ \\
\hline
\end{tabular}

